
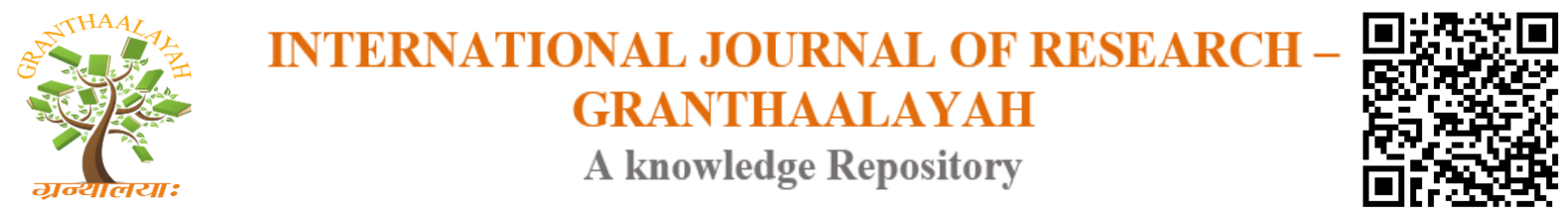

Social

\title{
SON PREFERENCE AND DAUGHTER NEGLECT: GENDER DISCRIMINATION IN HARYANA
}

\author{
Seema Devi *1 \\ ${ }^{* 1}$ Research Scholar, IMSAR, MDU, Rohtak, Haryana, INDIA
}

DOI: https://doi.org/10.29121/granthaalayah.v4.i11.2016.2431

\section{ABSTRACT}

While common people prick-up ears the name "Haryana", it pleasure them resembling being that is knit together to flowers, blossom, greenery; on friendly terms dwelling to live and masses are pleasant, conducive nevertheless the nuts and bolts is disparate. The blush of land is "Red" and people are murders. Their including finger dukes are "Red" with "Blood" of female feticide. Haryana is solitary economically well-heeled while it move towards societal buildup, it is lifeless turned around on the point of cast back to intrinsic nethermost 914 girls for 1000 boys in the age mess of 0-6 years on the point of census. The indicated remarkably twisted infant femininity proportion is the gigantic curse for growing state alike Haryana. Regularly turn thumbs down masculinity rate teem with pretended many-a-moon dangerous segment along gender-friendly districts facing down streams. The sound mind of this evil is mightily grounded in culture, social norms, family values, religion etc. This paper examines the dominant reasons for son preference and daughter neglect in Haryana, its implications on society and to give suggestion to overcome the situation.

Keywords:

Haryana, Son preference, daughter neglect.

Cite This Article: Seema Devi, "SON PREFERENCE AND DAUGHTER NEGLECT: GENDER DISCRIMINATION IN HARYANA" International Journal of Research Granthaalayah, Vol. 4, No. 11 (2016): 137-145.

\section{INTRODUCTION}

Women are not going to be equal outside the home

$$
\text { Until }
$$

Men are equal in it

-Gloria Steinem

Sex ratio is a barometer or index that illustrates the place of women in society. Ministry of Home Affairs, Government of India defines sex ratio as, "Sex ratio is the number of females per thousand males. It is an important and useful indicator to assess relative excess of deficit of men 
or women in a given population at that point of time". The place which is known for its respect for women nationwide is becomes a place where girls are not safe even in mother's womb. The smoking gun showing that there not by any means social dignity as girl children. No end of academic work in Haryana presents that girls child sex ratio in entire population had without exception stable unfavorably. Indian census 2001 and 2011 reviews disproportion of child sex ratio in Haryana. Even giving birth to girl child is a matter of survival or death for mother in several districts of Haryana. The Supreme Court of India announced 2007 as the female feticide awareness year but after the 8 year of declaration the child sex ratio in India is declining over the period and at the lowest since 1947 from 946 girls to 918 girls per 1000 boys on the ground of son preference (Census of India, 2011). But the current census (2011) brought to light the child sex ratio in Haryana is slight increase from 2001 i.e. 819 to 830 number of girls as per 1000 boys of 0-6 age group (Census of India, 2011). A gentlewoman frames the wheel of fortune of enlightenment. This is the humor of divine will, that the lovely imagination of God, a girl child is present day matter of gravest worry facing by society, amidst a storm of events, seminars, workshops, conferences and research papers adhered for the motivation, along dominant world dignitary at the driver's seat. Unwritten laws and customs blueprint the big game of Indian girl child, with free-for-all of gender parity and law obligation feminine newborn are deathly quiet found throw down in odds and ends, by the dozens, though out the time developing infants keep the ball rolling to be sniffed in womb. Molded with injustice and inequity by rituals, the civilization take the girl child with a bearded grasp and this has been started right in days of yore birth until the dark of life. In India especially in North side like Haryana, Rajasthan, Utter Pradesh; boys are breast-feed prolonged than girls. (Karnataka report 2015). Because of the parent's eagerness having boy child. Girls with older blood sisters are probably to deteriorate in string of fitness as well as nourishment.

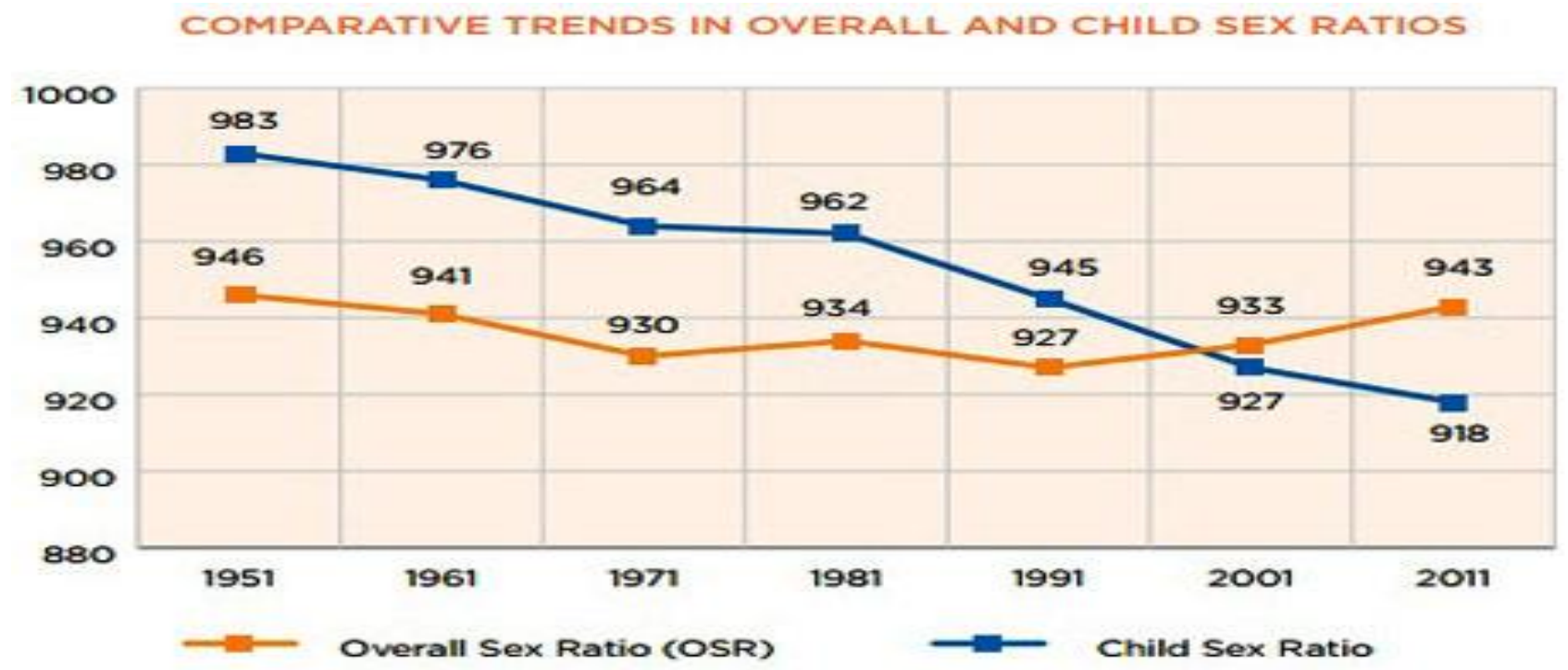

Figure 1: Comparative trends in Overall Sex Ratio and Child Sex Ratio in India Source: Census of India, 2011

From above figure it is clear that there is disparity between girls and boys in India. Child sex ratio is in declining trend which reduced from 983 to 918 in 2011. 


\section{REVIEW OF LITERATURE}

Suman Chauhan, Sunil Kumar, Anju Gupta in research paper titled "A Declining Child Sex Ratio in Haryana: A Spatio-Temporal Analysis" defines the sex composition in India, special reference to Haryana. This study examines the spatio-temporal fluctuation in rural and urban areas of Haryana in child sex ratio. The interpretation reveals that the sex ratio declining from 1991-2001 but a slight increment in 2011 as per census of India, 2011.

In article "Sex Ratio of Haryana: A Geographical Analysis" the author's Jagdeep Kumar and Shilpa Devi want to examine the indicator of demographic status of women through mortality, marital status, migration, economic characteristics etc. the objective of the paper is to analyses the tendency of all districts of Haryana and policies adopted by government to improve sex ratio with some suggestions. The major findings show the negligible increment in sex ratio in Haryana from 870 (1981) to 877 (2011).

In her paper Aparna Mitra "Son Preference in India: Implication for Gender Development try to give reason, why in spite of increasing literacy rate, well-fledged education, health care facilities and income status, the people give preference to son and neglect the girl child. By using data from National Family Health Survey (NFHS) and Census of India, find out the child sex ratio of age group 0-6 year is constantly declining only because of son preference. The lawmakers should reinforce the code of conduct and rules \& regulations to move the girl child from grave for son preference, feticide or decreasing value of girl in India.

According to Kamal and Ashish Kumar study on "Declining in Child Sex Ratio: Challenges, Causes and Emerging Issues in Haryana" examine the objection, reasons, tendency and rising issues in child sex ratio in Haryana. The main problem found is social security of girl child, son preference, ground level education in rural areas and society against female decisions etc. The findings indicate decreasing and imbalance in child sex ratio in Haryana in comparison of 2001 to 2011.

The paper "Child Sex Ratio in Jhajjar District (Haryana): A Spatio-Temporal Analysis" by Monu Kumar show the adverse drop of child sex ratio by 128 points from 902 to 774 girls per 1000 boys as reported by all tehsils of Jhajjar district. Arc Gis 9.3 software is used for analyzing the data from 2001-2011.

Leela Visaria (2008), describe the challenges to be faced in near future by government to implement policy and advocy. To protect India from the giant who eat the female child and decreasing woman population in India. The finding shows that the role of Association and Federation of Obstetricians and Gynecologists is crucial to prevent increasing deficit of women in the population.

Rohini Pande and Anju Malhotra in paper "Son preference and Daughter neglect in India: What happens to living girls?" reveal the culture and ideology behind the son preference in India as well as the factors influencing the diminishing the strength of women in India. After applying the multivariate analysis, the key findings are: the mother wants balance of boy and girl, one and only factor that influence the decision is mother's education, son preference does not depend on 
social and economic development, and girls having older sisters face more health problems because of nutrition.

Reeve Vanneman, Sonalde Desai, Kriti Vikram in article "Son preference in India" taking the data from India Human Development Survey, 2005 try to investigate six different reasons of son preference. The findings indicate "attitudes" towards female child is most important factor that influences the decision.

Nadia Diamond-Smith, Nancy Luke, Stephen Mcgarvey in "Too many girls, too much dowry: son preference and daughters aversion in rural Tamil Nadu, India" dictate that the South India experienced drastic deficit in girl child sex ratio and extended tendency of son preference. The findings are based on interviews with women in rural areas for their fertility decisions. Women use numerous methods to control girl child birth.

"Save the girl child initiatives in India-A social marketing perspective" by Ashish Sadh and Payal S. Kapor describe the situation is worst because of lack of awareness among people. This social can be controlled by social change campaigns, properly implemented States and Central Government rules. All schemes should target the rural areas and illiterate people.

National Institute of Public Cooperation and Girl Development (2008) on "A Socio-Cultural Study of the Declining Sex Ratio in Delhi and Haryana" report that in patriarchal society people give preference to son which leads to infancy and feticide. The discrimination against girl child begins before the birth as ultrasound machines and advance technologies help in sex determination.

Sub Group Report on 'Girl Child in the Eleventh Five Year Plan (2007-2012)' by Ministry of Women and Child Development Government of India describe current status of girl child in India. According to Human Development Indicators (HDI), female feticide and infanticide are primarily reasons for swiftly declining of girl sex ratio in Haryana, Punjab and other states. The declining health of girls is not only just because of poverty but also the value and attachment with girls.

Sutapa Agrawal in article "Discrimination against Girl Child in Rural Haryana, India: From Conception through Childhood" (2002) highlights the condition of girl child in Haryana by approaching five villages. The findings indicate that the mother's education, exposure of social media, marital instability has negative influence on child sex ratio in Haryana.

Sayeed Unisaa (2009) in article "An Investigation into Masculinization of Sex Ratio in India" presents the situation of Indian states in declining fertility or child sex ratio. Census data from 1971-2001 has been taken to explore the reason of changing Female to Male Sex (FMS) Ratio. The findings shows except Punjab, Haryana, Himachal Pradesh, Gujarat and Maharashtra, there is less discrimination against girl child

"Discrimination of female children in modern India: from conception through childhood" by T.V.Sekher and Neelambar Hatti try to reveal the deep-rooted mind of people even in modern society. According to the research there are main three reasons of discrimination against female 
child are infanticide, neglect the girls, and unwanted abortion. To supervise the position government should proceed with effective steps.

\section{APPROACH AND METHODOLOGY}

The study is planted on secondary sources and that is taken from Ministry of Home Affairs, Government of India, Census of India, statistical abstract of child sex ratio, books, journals, newspapers, etc. Haryana state has been selected for the purpose of investigation. Numerous research papers bring out to study the position of girls in India as well as Haryana. These writings test the disparate condition link with root and ramification of sex option. The paper is conceptual in nature.

\section{OBJECTIVES}

- To inquiry the tendency of sex ratio in districts of Haryana.

- To analyze the dominant reasons of child discrimination in Haryana.

- To check out the steps or action taken by Government to protect child sex ratio.

- To offer few suggestions to increase child sex ratio.

\section{SEX RATIO IN HARYANA}

In distinction to opening of population tally list in nation, India's populace is tremendous increases. India, after China (1.357 billion) population, is at second place with population 1.252 billion. But from the very beginning there is thriving deficit of females in India. This paucity is an eyewitness of increasing crime against women. Haryana after Punjab is at second place in declining child sex ratio of age group 0-6 years the regular childbirth sex ratios settle up in the middle 819 and 830 girls per 1000 boys (Census of India, 2011). For verifying the fluctuations in child sex ratio a comparison of all districts is done. Haryana has entire population of 2.5 crore with male population 1.35 crore and female population 1.18 crore. Haryana's sex ratio is $877: 1000$.

Table 1: Comparative Sex Ratio, Child Sex Ratio of Haryana Districts.

\begin{tabular}{|c|c|c|c|c|c|c|c|c|c|}
\hline \multirow[t]{2}{*}{ State/Distrct } & \multirow{2}{*}{$\begin{array}{l}\text { Sex Ratio } \\
1971\end{array}$} & \multirow{2}{*}{$\begin{array}{l}\text { Sex Ratio } \\
1981\end{array}$} & \multirow{2}{*}{$\begin{array}{l}\text { Sex Ratio } \\
1991\end{array}$} & \multicolumn{2}{|c|}{ Sex Ratio } & \multicolumn{2}{|c|}{$\begin{array}{l}\text { Percent 0-6 } \\
\text { pop }\end{array}$} & \multicolumn{2}{|c|}{$\begin{array}{l}\text { Sex Ratio } \\
\text { 0-6 pop }\end{array}$} \\
\hline & & & & 2001 & 2011 & 2001 & 2011 & 2001 & 2011 \\
\hline HARYANA & 867 & 870 & 865 & 861 & 877 & 15.8 & 13.0 & 819 & 830 \\
\hline Panchkula & 819 & 833 & 839 & 823 & 870 & 14.1 & 11.7 & 829 & 850 \\
\hline Ambala & 882 & 902 & 903 & 868 & 882 & 13.2 & 10.9 & 782 & 807 \\
\hline Yamunanagar & 848 & 855 & 883 & 862 & 877 & 14.4 & 11.8 & 806 & 825 \\
\hline Kurukshetra & 859 & 872 & 879 & 866 & 889 & 14.2 & 12.0 & 771 & 817 \\
\hline
\end{tabular}




\begin{tabular}{|l|l|l|l|l|l|l|l|l|l|}
\hline Kaithal & 843 & 848 & 853 & 853 & 880 & 15.4 & 12.6 & 791 & 821 \\
\hline Karnal & 856 & 856 & 864 & 865 & 886 & 15.1 & 12.9 & 809 & 820 \\
\hline Panipat & 852 & 849 & 852 & 829 & 861 & 16.4 & 13.7 & 809 & 833 \\
\hline Sonipat & 866 & 866 & 840 & 839 & 853 & 15.4 & 12.7 & 788 & 790 \\
\hline Jind & 860 & 857 & 838 & 852 & 870 & 15.8 & 12.4 & 818 & 835 \\
\hline Fatehabad & 870 & 881 & 877 & 884 & 903 & 16.1 & 12.6 & 828 & 845 \\
\hline Sirsa & 865 & 877 & 885 & 882 & 896 & 15.0 & 11.9 & 817 & 852 \\
\hline Hisar & 859 & 859 & 853 & 851 & 871 & 15.5 & 12.1 & 832 & 849 \\
\hline Bhiwani & 878 & 897 & 878 & 879 & 884 & 15.7 & 12.6 & 841 & 831 \\
\hline Rohtak & 878 & 869 & 849 & 847 & 868 & 14.5 & 11.9 & 799 & 807 \\
\hline Jhajjar & 903 & 891 & 861 & 847 & 861 & 15.0 & 12.1 & 801 & 774 \\
\hline Mahendragarh & 910 & 939 & 910 & 918 & 894 & 15.8 & 11.9 & 818 & 778 \\
\hline Rewari & 927 & 926 & 927 & 899 & 898 & 15.2 & 12.5 & 811 & 784 \\
\hline Gurgaon & 886 & 880 & 871 & 850 & 853 & 15.5 & 13.1 & 807 & 826 \\
\hline Mewat & $\mathrm{NA}$ & $\mathrm{NA}$ & $\mathrm{NA}$ & 899 & 906 & 25.1 & 22.3 & 893 & 903 \\
\hline Faridabad & 810 & 811 & 828 & 826 & 871 & 15.8 & 13.2 & 847 & 842 \\
\hline Palwal & $\mathrm{NA}$ & $\mathrm{NA}$ & $\mathrm{NA}$ & 862 & 879 & 20.0 & 16.5 & 854 & 862 \\
\hline
\end{tabular}

Census of India, 2011

Table 2: Highest and Lowest Child Sex Ratio Districts of Haryana.

Highest Child Sex Ratio (0-6) Districts:

\begin{tabular}{|l|l|l|}
\hline S. NO. & DISTRICTS & SEX RATIO \\
\hline 1 & MEWAT & 903 \\
\hline 2 & PALWAL & 862 \\
\hline 3 & SIRSA & 852 \\
\hline 4 & PANCHKULA & 850 \\
\hline 5 & HISAR & 849 \\
\hline
\end{tabular}

Census of India, 2011

Lowest Child Sex Ratio (0-6) Districts:

\begin{tabular}{|l|l|l|}
\hline S. NO. & DISTRICTS & SEX RATIO \\
\hline 1 & JHAJJAR & 774 \\
\hline
\end{tabular}




\begin{tabular}{|l|l|l|}
\hline 2 & MAHENDERAGHRAH & 778 \\
\hline 3 & REWARI & 784 \\
\hline 4 & SONEPAT & 790 \\
\hline 5 & ROHTAK, AMBALA & 807 \\
\hline
\end{tabular}

Source: Census of India, 2011

\section{REASONS FOR SON PREFERENCES AND DAUGHTER NEGLECT IN HARYANA}

Indian civilization is deathly still hesitant facing girl child toward boy. The girls are unwelcome because of following reasons:

- The uncommon inference of son desire may be, in comparison to female child male child take care of family businesses and parents in the time of old age and prospect of preferred income in industry.

- A son after marriage brings up dowry rather depleting inheritance ways and means in Haryana. The people think that "Too many girls, too many dowry". Girl family financial status inform of dowry is run-of-the-mill in North India in opposition to South India. In South all marriage ceremony cost is divided between bride and grooms families. This tradition or ritual in Haryana put in plain English the value of women in North India in comparison to South India like Kerala.

- The son has only right of cremation of his family by the virtue of Hindu mythology only son can pass out "Moksha" to his father and mother.

- The narrow minded people beat the drum when a "Lalla" (son) take birth in family and pay attention to mother with dignity and honor.

- From the birth till the death, a woman is secured by male member of her family like before marriage protested by father and brother or after marriage protected by husband. Even she has no right to use its own surname; she is called by her husband surname.

- Investment in son education is considered as capital or future asset while payment for girl's education fee is bad debt on the ground of the future benefits. As the result her education expenses or cost reduce the family resources.

- The girls after marriage swiftly come in strong arm of her in-laws and their desire to expand the family. They have no right to take decision for her life. She is considered like a "thing" just take and put from her birth. So, the parents are more attached with son. Son preference emerges as necessity covered by way of life.

\section{GOVERNMENT'S INITIATIVES FOR THE INCREASE OF SEX RATIO}

1) “Apki Beti Humari Beti"- scheme: to solve the problem of declining child sex ratio, this scheme is put on motion by present Chief Minister Manohar Lal Kattar on 8 March, 2015 on occasion of International Women's Day at Panchkula. This scheme cover the SC (scheduled cast) and BPL (below poverty line) facilities. The scheme put into words, "First girl child born on or after Jan. 22, 2015, in SC and BPL families will be eligible to receive Rs. 21,000 and second girl born on or after Jan. 22, 2015 of all families will get Rs. 21,000. The families, where twin girls or multiple girls are born, will get Rs. 21,000 per child, the statement said". 
2) "Selfie with daughter in Haryana"- Haryana state is suffering from disease called female feticide. To protect the state from this fierce disease, Chief Minister, Manohar Lal Khatter start contest "Selfie with Daughter" to make restitution of misshape girl sex ratio on 28 June, 2015 with launching this scheme at national level.

3) "Kanya Kosh"- In Panipat on 22 January, 2015, Chief Minister of Haryana, Manohar Lal Khatter launch "Haryana Kanya Kosh" scheme for providing financial help on first girl childbirth of poor and scheduled cast families.

4) "The Ladli Scheme"- The purpose behind launching this scheme is to keep tight rein on female feticide by developing their ways for education and reducing discrimination. This scheme is sponsored by SBI (State Bank of India), under which an amount of 10,000 will be deposited with opening of account and rest Rs. 5,000 will be with girl child.

5) "Sable Scheme"- This scheme launched for blessing teen age girls. The government initiates to come back the out-of-school girls in any type of formal or informal education.

6) "Dhanalakshmi Scheme"- To provide financial assistance with insurance "Dhanalakshmi Scheme" launched in 2008. This scheme design immediate transfer of some cash amount after fulfilling some basic requirement like birth, registration, immunization etc.

\section{SUGGESTIONS}

From 1971 Haryana's child sex ratio show declining tendency but in 2011 there is a little bit increment in ratio. This increment is not the indicator of development of human index but a signal of doing a lot of actions towards growth of humanity. There are some suggestions to improve child sex ratio in Haryana:

- The policies and Acts introduced by Government as Pre-Natal Diagnostic Technique (PNDT), Medical Termination of Pregnancy (MTP) should be delivered in elucidatory and understandable language to common people. Misinterpretation and elusiveness

- DPA (Dowry Prohibition Act) should be effectively implemented and strictly regulated; the punishment should be iron-fisted for non-following the rules.

- Financial independency of girls via promoting them to join jobs and services should be supported and ensured.

- Right to Education Act should be appliance properly for compulsory and free education to girl child.

- Awareness campaigns, workshops, seminars and other required measures to make people aware about the need of women empowerment should be spreaded.

- The most important thing, the way of thinking of people should be change, they should not be considered as burden.

\section{CONCLUSION}

In a nutshell, the present study rehashes that the so called progress and modernization of sovereign India with Modi's buzz words "Sabka Sath, Sabka Vikas, Ache Din and so on, is all phony and façade until or unless the women, half of the world population do not get their respective status, rights, status, freedom and representation. The present criticism does not rule out the possibility of progress in this arena but still there are certain grey areas which need to be attended and addressed. Particularly, the situation of women and girl child in rural hinterland 
needs government's attention. The need of the hours is that in spite of passing general rules and policies government should witch-hunt the most retrogressive atavistic, traditional and arthodoxical region which are anti-progress and should direct their energy and finance to reform them to bring the society on even keel.

\section{REFERENCES}

[1] Censusinindia.gov.in/census-and-you/gender-composition.aspx.

[2] Censusinindia.gov.in/2011-prov-results/data-files/Haryana/4-table2.doc

[3] Chauhan, S., Kumar, S., \& Gupta, A. (2016, June). A declining child sex ratio in Haryana: A Spatio-Temporal Analysis. International Journal of Interdisciplinary Research in Science Society and Culture (IJIRSSC), Vol. 2(Issue 1), Pp.379-390.

[4] Diamond, N., Luke, N., \& Mcgarvey, S. (2008, October). 'Too many girls, too much dowry': Son preference and daughter aversion in rural Tamil Nadu, India. NIH Public Access, VOL. 10(7), Pp. 697-708. doi:doi:10.1080/13691050802061665.

[5] Haryana to set up Kanya Kosh for first girl child. (n.d.). The Economics Times. Retrieved August 19, 2016, from articles.economictimes.indiatimes.com/2015-0122/news/58344453_1-girl-child-beti-bachaoo-beti-padhao-literacy-rate

[6] Kamal., \& Kumar, A. (2014). Declining in child Sex Ratio: Challenges, Causes and Emerging Issues In Haryana. International Journal on Arts, Management and Humanities, Vol. 3(Issue 1), Pp.44-48.

[7] Kumar, J., \& Devi, S. (2013, December). Sex ratio of Haryana: A Geographical Analysis. International Global Research Analysis, Vol. 2(Issue 12), pp. 76-78. Retrieved August 12, 2016.

[8] Kumar, M. (2013, November). Child sex ratio in Jhajjar district (Haryana): A spatiotemporal analysis. International Index \& Refereed Research Journal, Vol. 5(Issue 58), Pp 8-11.

[9] Mitra, A. (n.d.). Son Preference In India: Implications For Gender Development. Retrieved August 10, 2016.

[10] Pande, R., \& Malhotra, A. (n.d.). Son Preferen and Daughter Neglect in India. International Center for Research on Women. Retrieved August 11, 2016.

[11] Sadh, A., \& Kapoor, P. S. (2012, October/November). Save the Girl Child Initiatives in India A Social Marketing Perspective. IMJ, Vol. 4(Issue 3), Pp-18-34.

[12] Sharma, B. (n.d.). Selfie with daughter contest in Haryana- A terrific step towards restoring skewed esx ratio. The Huffington Post. Retrieved August 15, 2016, from www.huffingtonpost.in/2015/06/28/modi-announces-father-daughter-selfie-campaign-forthe-girl-child/

[13] TimesofIndia.indiatimes.com/india/Apki-Beti-Humari-Beti-scheme-launched-inHaryana/articleshow/46494650.cms.

[14] Vanneman, R., Desai, S., \& Vikram, K. (n.d.). Son Preference in India. Retrieved August 1, 2016, from file:///H:/beti/New folder/son best.pdf.

[15] Visaria, L. (2008, March/April). Improving the Child Sex Ratio: Role of Policy and Advocacy. Economic and Political Weekly, Vol. 43(No. 12/13), Pp. 34-37. Retrieved from http://www.jstor.org/stable/4027728

[16] Web-site=yojana.gov.in/CMS/pdf/yojana/English/2011/yojana\%20July\%202011.pdf.

[17] www.savegirlchild.org. 